"The adoption of tablet PCs by South African college students: an application of the technology acceptance model"

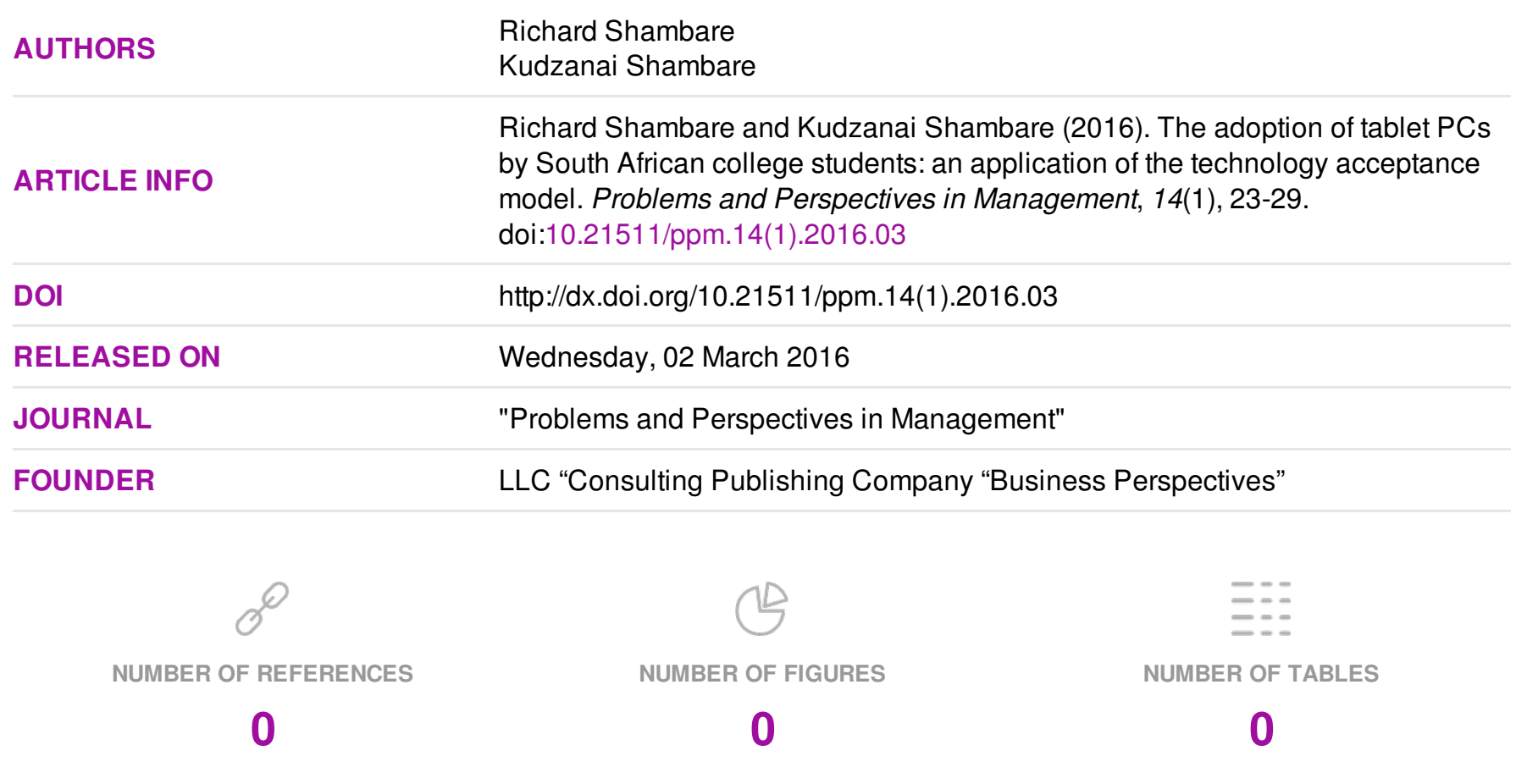

(C) The author(s) 2023. This publication is an open access article. 


\title{
The adoption of tablet PCs by South African college students: an application of the technology acceptance model
}

\begin{abstract}
This paper reports the results of a study that investigated South African tertiary education students' adoption patterns of tablet PCs as an e-learning medium. Utilizing structural equation modelling techniques, the study tested the hypothesized effects of perceived ease of use and perceived usefulness, two constituent variables of the technology acceptance model (TAM), to predict the adoption of tablet PCs among college students. Self-completion questionnaires were used to collect data from a sample of 344 students from a South African college. From the study, two important findings were made. First, the association of innovation awareness and adoption was established. Second, the relationship among perceived ease of use, perceived usefulness, and the adoption of new technology in situations involving discontinuous innovations is clarified. In addition, the study makes two contributions. It is the first to utilize structural equation modelling to study the adoption of tablet PCs within the context of e-learning in South Africa. More importantly, the study develops a technology usage model for discontinuous e-learning innovations.
\end{abstract}

Keywords: adoption, education, e-learning, structural equation modelling, South Africa, tablet PC, technology acceptance model.

JEL Classification: M15, M390.

\section{Introduction}

To promote learning, many South African institutions of higher education provide their learners with electronic handheld devices such as tablet PCs. These devices are pre-loaded with electronic versions of prescribed textbooks and study material, which serve as: (1) electronic repositories of study material, (2) word processors for note-taking and (3) mobile Internet devices. The efficacy of hi-tech devices such as tablets within an education setting is that they are in line with the technological demands of today's students (Shambare \& Mvula, 2011). Modern students prefer to stay connected to the Internet for the purposes of self-discovery and learning, whereas older generations consider the Internet just another alternative source of knowledge (Hooper \& Zhou, 2007; Shambare \& Mvula, 2011). The introduction of hi-tech devices such as tablet PCs in higher education is likely to make learning more interesting and meaningful to students (Banister, 2010; Masrom, 2007). While tablets do not replace traditional teaching methods, it is envisaged that they provide new opportunities for interaction between students, educational content, and instructors (Sabry \& Al Shawi, 2008).

Tablet PCs are multi-function machines; within the context of e-learning, they fundamentally perform three functions (Banister, 2010). Firstly, they are electronic repositories of study material, which includes electronic books (eBooks), course modules, PowerPoint slides, and other class activities and notes.

(C) Richard Shambare, Kudzanai Shambare, 2015.

Richard Shambare, Senior Lecturer in the Department of Business Management, University of Venda, South Africa.

Kudzanai Shambare, Senior Programmes Director, Fulbright Academy, South Africa.
Given the escalating costs associated with textbooks and printing, it is envisaged that tablet PCs should provide students with all the information they require for their studies at their fingertips. Secondly, tablet PCs can be used for note-taking and word processing. The former can be used in class during lectures in conjunction with applications such as Evernote. In the case of the latter, assignments and projects can be drafted easily without having to use a separate device in the form of a laptop or desktop computer. Thirdly, the tablet PC is a mobile Internet device. This empowers students to have instant Internet access, which can be used for information searches on platforms such as Google (Nicholas et al., 2010). Since they support the Internet, applications can be utilized to enhance communication and interaction with fellow students as well as with course instructors (Sabry \& Al Shawi, 2008).

There are many examples in the literature reporting on experiences of e-learning, however, research in developing countries such as South Africa is still limited. This research broadens the scope of research in the area.

\section{Context and background}

The current study was undertaken at the Rosebank College (RC), Pretoria Campus. RC is one of five campuses in South Africa and is an affiliate of the Independent Institute of Education (IIE), the largest privately-owned higher education institution (HEIs) in South Africa. At the time of the study, RC's enrolment stood at approximately 1, 200 students in numerous courses in business, IT, and law at certificate and diploma levels.

Traditionally, all RC's learning material was provided in printed, paper-based format. RC 
introduced e-learning when it provided its students with tablet PCs upon registration in the beginning of the 2012 academic year. Given the popularity of mobile electronic devices, the move was also part of a broader marketing strategy to attract prospective students to the institution. With the introduction of the Lifepad tablet, learning materials were loaded electronically onto the students' tablets. Since paper-based learning materials were not issued, students relied only on the tablets to access study materials. However, about two to three months into the year, a significant proportion of students expressed dissatisfaction with the new e-learning devices and many began requesting paper-based learning material. Since then, usage rates of tablet PCs among RC students have steadily declined. Overall, the adoption rate of the tablet $\mathrm{PC}$ at $\mathrm{RC}$ has been much lower than expected, and presents questions about the factors which influence adoption of e-learning approaches.

\section{Research objectives}

The introduction of tablet PCs at RC can be considered to be a new e-learning innovation in that students are using this new technology in a learning environment (Rogers, 1995). It is against this background that it was opportune to study the factors influencing the adoption of tablet PCs - a new e-learning innovation within the context of an HEI in an emerging economy setting.

The rest of the paper is structured as follows. In the following section, the literature as it pertains to e- learning technologies as well as the proposed theoretical model is presented. Next, the methodology applied to test hypotheses is discussed. Results and findings are presented thereafter, followed by conclusions and discussion.

\section{Literature review}

3.1. Tablet PCs and e-learning. Tablet PCs are multi-function mobile devices. Most of the functions performed on mobile phones and laptops including word processing, working on spreadsheets, taking pictures, and accessing the Internet can be performed with tablet PCs. Tablet PCs therefore are ideally primed for application in an educational setting as they can be used to take down notes, type assignments and for information research (Banister, 2010).

Effective learning takes place when students assimilate new knowledge on an on-going basis. Lavooy and Newlin (2003) demonstrate that computer mediated technologies such as tablet PCs not only allow for continuous learning interactions, between students and their educational content and instructors, but also deepen these interactions. According to Sabry and Al Shawi (2008), an interactive learning system (ILS) engages the learner with a variety of interactions with materials, peers and educators. Figure 1 shows the three main types of learning interactions: student-information (S-I), student-lecturer (S-L) and student-student (S$\mathrm{S})$, all of which are interactions, tablet PCs theoretically should enhance.

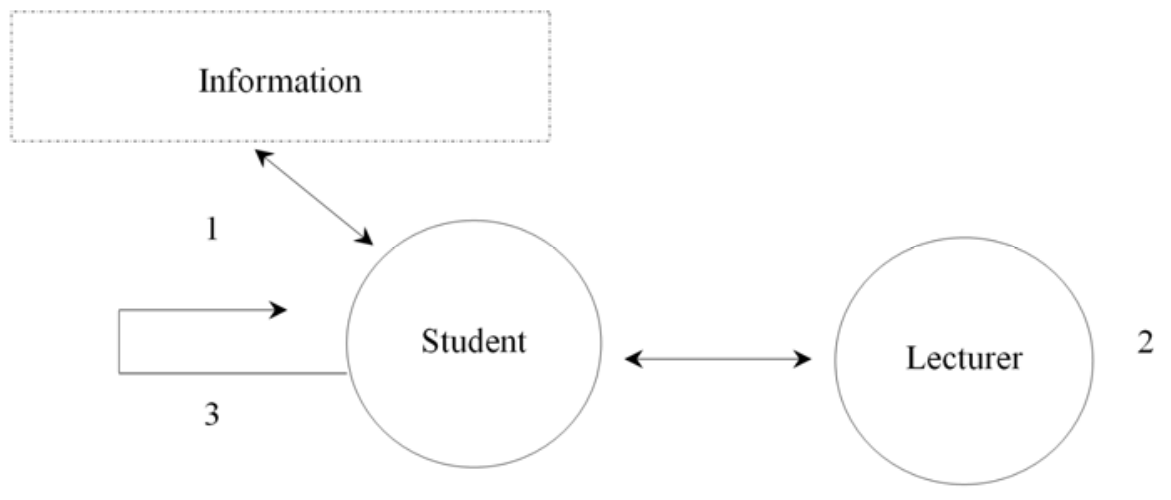

Fig. 1. Main types of ILS interaction

Source: Adapted from Sabry and Al Shawi (2008).

In this context, tablet PCs' ability to promote faster interchange of information among students on the one hand, and between students and lecturers on the other, potentially make it an important educational tool (Sabry \& Al Shawi, 2008).

3.2. Tablet PC adoption theoretical framework. The technology acceptance model (TAM) posits that individuals' beliefs and perceptions about an innovation influence their attitudes towards it, which in turn leads to behavioral intentions to adopt the innovation (Alrafi, 1989). TAM is widely applied in modelling attitudes and behavior related to the acceptance and rejection of technological innovations (Tanakinjal, 2006), and as a result, the model has received broad support in empirical studies of consumer decision making in ICT-related products (Alrafi, 1989; Walczuch, Lemmink \& Streukens, 2007), and therefore it was selected as most appropriate for studying tablet PC adoption. 
TAM posits that two determinant variables: perceived usefulness (PU) and perceived ease of use (PEU), are determinants of adoption (Figure 2) (Alrafi, 1989; Davis, 1989). PEU refers to users' perceptions of the amount of effort required to utilize an innovation. On the other hand, PU relates to the potential adopters' perceptions of the importance and usefulness of a particular technology (Alrafi, 1989; Tanakinjal, 2006). Although both variables are important in predicting adoption behavior (Ma and Liu, 2004) propose that PEU affects technology acceptance indirectly through PU.

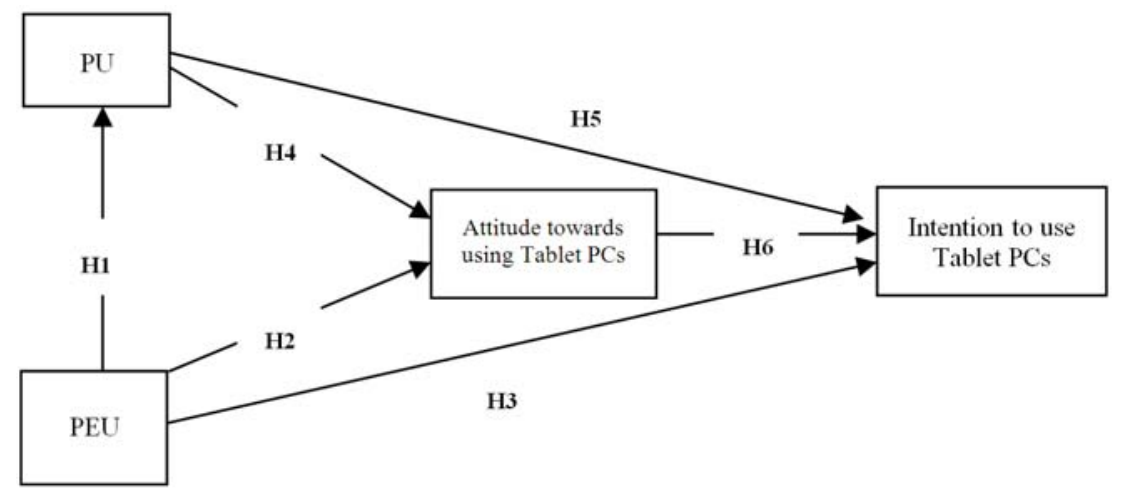

Fig. 2. Theoretical model of Tablet PC adoption

Based on the above conceptual frame, the following hypotheses were formulated:

$H_{1}$ - Perceived ease of use of tablet PCs has a significant effect on its perceived usefulness.

$\mathrm{H}_{2}$ - Perceived ease of use of tablet PC has a significant effect on attitude towards using tablet PC.

$H_{3}$ - Perceived ease of use of tablet PC has a significant effect on the intention towards using it.

$\mathrm{H}_{4}$ - Perceived usefulness has a significant effect on attitude towards using tablet PC.

$H_{5}$ - Perceived usefulness of tablet PC has a significant effect on the intention to use it.

$H_{6}-$ Attitude towards using tablet PC has a significant effect on the intention to use it.

\section{Research methodology}

A survey method was used to collect primary data from RC students between March and April 2012. Self-completion questionnaires were distributed in classroom settings. Participants were requested to complete the questionnaires at their convenience. Collection points were established at strategic places on the campus, where deposit boxes were placed. STATA 13 was used for data analysis (Blumberg, Cooper \& Schindler, 2011; Field, 2009).

4.1. Sample. The current study sought to investigate the adoption of tablet PCs by tertiary level students. For this reason, RC students were chosen. Given that the sample comprised of HEI students from a single campus (or a homogenous group), non-probabilistic sampling was utilized (Calder, Phillips \& Tybout, 1981). To determine the sample size, the requirements to conduct structural equation modelling (SEM) were taken into account. To successfully conduct SEM, each question (or item) that is to be analyzed ideally requires responses from at least 15 individuals. Thus, in keeping with 1:15 ratio requirement, an absolute minimum sample size of $\mathrm{n}=225$ (15 questions x 15 responses) was envisaged. In total, 500 questionnaires were distributed. Of these, 348 questionnaires were returned and only 344 were fully completed and usable, representing a 69 per cent response rate. Table 1 illustrates the participants' demographic characteristics.
Table 1. Demographic profile

\begin{tabular}{|l|l|c|}
\hline \multicolumn{2}{|c|}{ Demographic characteristics } & Percentage \\
\hline \multirow{2}{*}{ Gender } & Male & 41 \\
\cline { 2 - 3 } & Female & 59 \\
\hline \multirow{3}{*}{ Education level } & $1^{\text {st }}$ year & 52 \\
\cline { 2 - 3 } & $2^{\text {nd }}$ year & 39 \\
\cline { 2 - 3 } & $3^{\text {rd }}$ year & 9 \\
\hline \multirow{2}{*}{ Used tablet PC } & Yes & 79 \\
\cline { 2 - 3 } & No & 21 \\
\hline \multirow{3}{*}{ Tablet PC awareness } & $<6$ months & 69 \\
\cline { 2 - 3 } & $6-12$ months & 15 \\
\cline { 2 - 3 } & $>12$ months & 9 \\
\hline
\end{tabular}

\section{Results and discussion}

5.1. Awareness and use of tablet PCs. In terms of tablet PC awareness, about one-third ( 31 per cent) of the respondents indicated that they had known of tablet PCs for a period of at least six months. Given that the majority (69 per cent) only became aware of tablet PCs within the period up to six months of before the study may suggest that they only became aware of this technology when it was introduced at the school. This is in line with findings from Shambare and Mvula (2011), that diffusion and communication of innovations used by South African students takes place within the school environment.

Some 45 per cent of the respondents spent less than one hour a day on their tablet PCs. Approximately 30 per cent spent between one and three hours; the remaining 25 per cent used their tablet PCs for 
periods of more than three hours per day. It appears that participants using tablet PCs for periods of greater than three hours are those that have not only adopted them but also committed to their use as an e-learning tool. The chi-square test of association found this relationship to be significant $\left(\chi^{2}=11.365\right.$, $d f=3, p=.010)$.

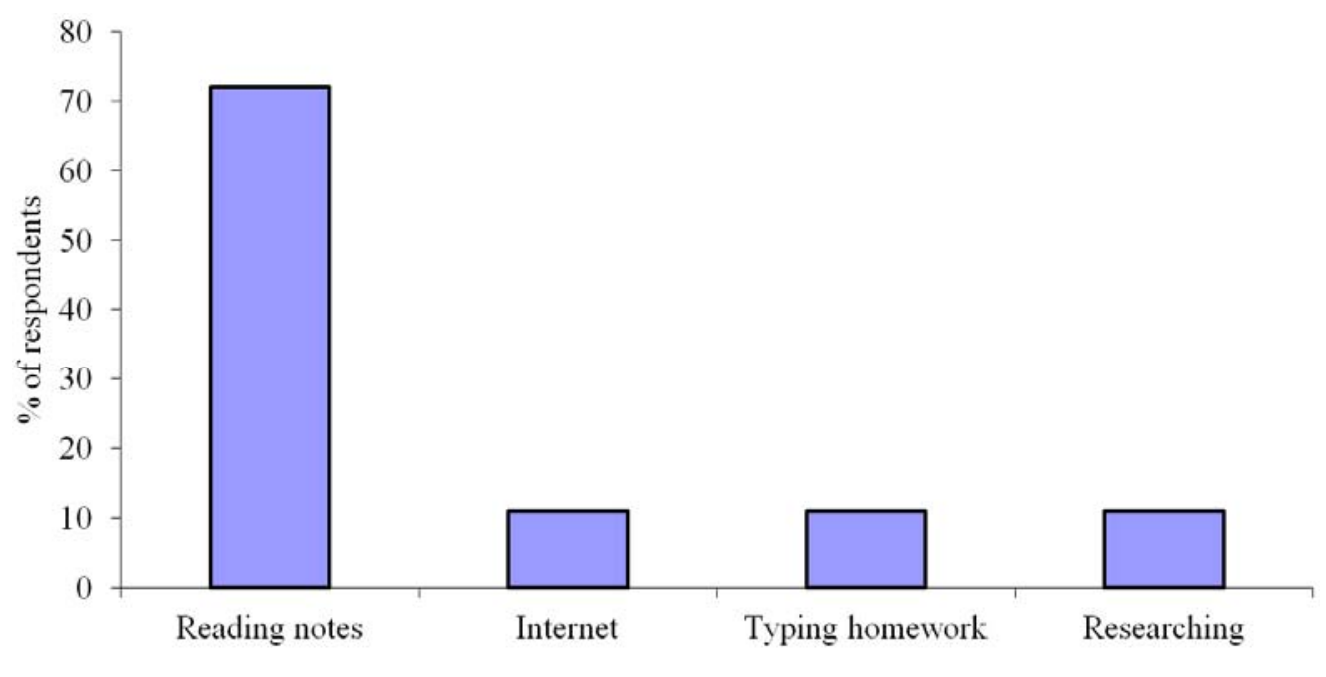

Tablet PC functions used
As shown in Figure 3, reading study notes proved to be the most popular tablet PC function. Almost three-quarters ( 72 per cent) of the sample indicated using the function. Usage of other applications was considered very low at about 11 per cent for browsing the Internet, typing homework, and researching, respectively.

Fig. 3. Tablet $P C$ applications used

Given that tablet PCs are versatile and multifunction devices that can be used for various applications including browsing the Internet and content creation, it appears that they are being under-utilized. This is especially surprising given the respondents are considered to be the 'Google Generation' in that they should be motivated to use hi-tech devices such as tablet PCs (Nicholas et al., 2010). Further investigation revealed that the version of tablet PC (Lifepad) provided to respondents requires wireless Internet connectivity (Wi-Fi) Internet connection, as they do not support SIM cards. At Rosebank College, however, Wi-Fi is not available. As such, students resort to other handheld devices including cell phones when connecting to the Internet. There are suggestions that the manner in which the tablet PCs were introduced to students only emphasized the functions of reading study material. The technology may not be extensively known, with the other features remaining largely unknown to students.

5.2. Tests of hypotheses using SEM. To ascertain determinants influencing the adoption of tablet PCs, the 15-item TAM scale refined by Masrom (2007) for e-learning contexts was adapted. The relationships among the key determinants of adoption, i.e., PEU, PU, attitude (ATT), and behavioral intention (BI), as proposed by TAM were used to formulate the six hypotheses shown in Figure 2. To obtain better explanatory power on how these variables relate to each other, SEM was used as opposed to regression analysis (Kline, 1998; Malhotra, 2010). Consistent with Malhotra's (2010) recommendations for conducting SEM analysis, a six-step approach was followed. This included (1) defining the individual constructs, (2) developing and specifying the measurement model, (3) evaluating the construct validity and reliability of the measurement model, (4) specifying the structural model, (5) assessing the structural model fit, and (6) making conclusions.

\subsubsection{Developing and assessing the measurement} model. The proposed theoretical model illustrated in Figure 2 was used to develop the measurement model. Figure 3 identifies PU, PEU, ATT, and BI as the four latent variables in the measurement model. However, this four-latent variable measurement model yielded poor fit $\left(\chi^{2}=160.961, p<.001\right.$; RMSEA $=.061$; P-close $=.077$ ). To improve the model fit, first all items with factor loadings less than .7 were removed from the model. Thereafter, the inspection of modification indices and covariance residuals suggested the removal of ATT, one of the four latent variables, from the measurement model as well as further analysis. The resultant three-factor model showed acceptable fit (see Table 2), as indicated by the goodness of fit indices that exceeded the minimum thresholds of $\chi^{2} / d f<3$, CFI $>.9$, RMSEA $<.5$, SRMR $<.08$, and P-close > .05 (Hair, Black, Babin \& Anderson, 2010; Kline, 1998). 
Table 2. Goodness of fit indices of the measurement model

\begin{tabular}{|l|c|}
\hline \multicolumn{1}{|c|}{ Fit index } & Value \\
\hline$X^{2}$ & 37.085 \\
\hline $\mathrm{df}$ & 29 \\
\hline $\mathrm{X}^{2} / \mathrm{df}$ & 1.28 \\
\hline $\mathrm{CFI}$ & .996 \\
\hline RMSEA & .028 \\
\hline P-Close & .922 \\
\hline SRMR & .029 \\
\hline CD & .989 \\
\hline
\end{tabular}

Having established a good fit in the measurement model, the next step was to test the model's validity and reliability. To this end, the average variance extracted (AVE) and the composite reliability (CR) were determined (Hair et al., 2010; Malhotra, 2010; Rammile \& Nel, 2012). The AVE is a summary measure of convergence, and provides details on how much variance, within a factor, can be attributed to the constituent items of that factor. Hair et al. (2010, p. 709) advise that, as a good practice, .5 is the absolute minimum acceptable AVE when assessing measurement models' validity. Table 3 demonstrates that this criterion was sufficiently met. CR measures the internal consistency of items within each construct. A CR of .7 or higher is considered to be appropriate for SEM applications. Table 3 shows that all the three constructs were greater than .7, and indicated high levels of reliability.
Table 3. Validity and reliability of measurement model

\begin{tabular}{|c|l|c|c|c|}
\hline Construct & \multicolumn{1}{|c|}{ Item } & Item loading & AVE & CR \\
\hline \multirow{3}{*}{$\begin{array}{l}\text { Perceived ease } \\
\text { of use }\end{array}$} & PEU1 & .79 & .63 & .78 \\
\cline { 2 - 5 } & PEU2 & .81 & & \\
\cline { 2 - 5 } & PEU3 & .78 & & \\
\hline \multirow{4}{*}{$\begin{array}{l}\text { Perceived } \\
\text { usefulness }\end{array}$} & PU1 & .70 & .59 & .80 \\
\cline { 2 - 5 } & PU2 & .84 & & \\
\cline { 2 - 5 } & PU3 & .79 & & \\
\cline { 2 - 5 } & PU4 & .73 & & \\
\hline \multirow{3}{*}{$\begin{array}{l}\text { Behavioral } \\
\text { intention }\end{array}$} & B11 & .78 & .61 & .71 \\
\cline { 2 - 5 } & BI2 & .79 & & \\
\cline { 2 - 5 } & BI3 & 77 & & \\
\hline
\end{tabular}

5.2.2. Structural model. Consistent with the threefactor measurement model (Table 3), the structural model was specified. Given that the theoretical model in Figure 2 suggested the existence of two independent variables (PEU and PU), it was prudent to test such a model in which both PEU and PU were exogenous variables. Such a model, however, was observed to have poor fit. Model improvement using modification indices resulted in the structural model depicted in Figure 4. The resultant goodness of fit indices showed a good fit $\left(\chi^{2} / \mathrm{df}=1.24 ; \mathrm{CFI}=\right.$ .996 ; RMSEA = .026; SRMR = .030; P-Close .944).

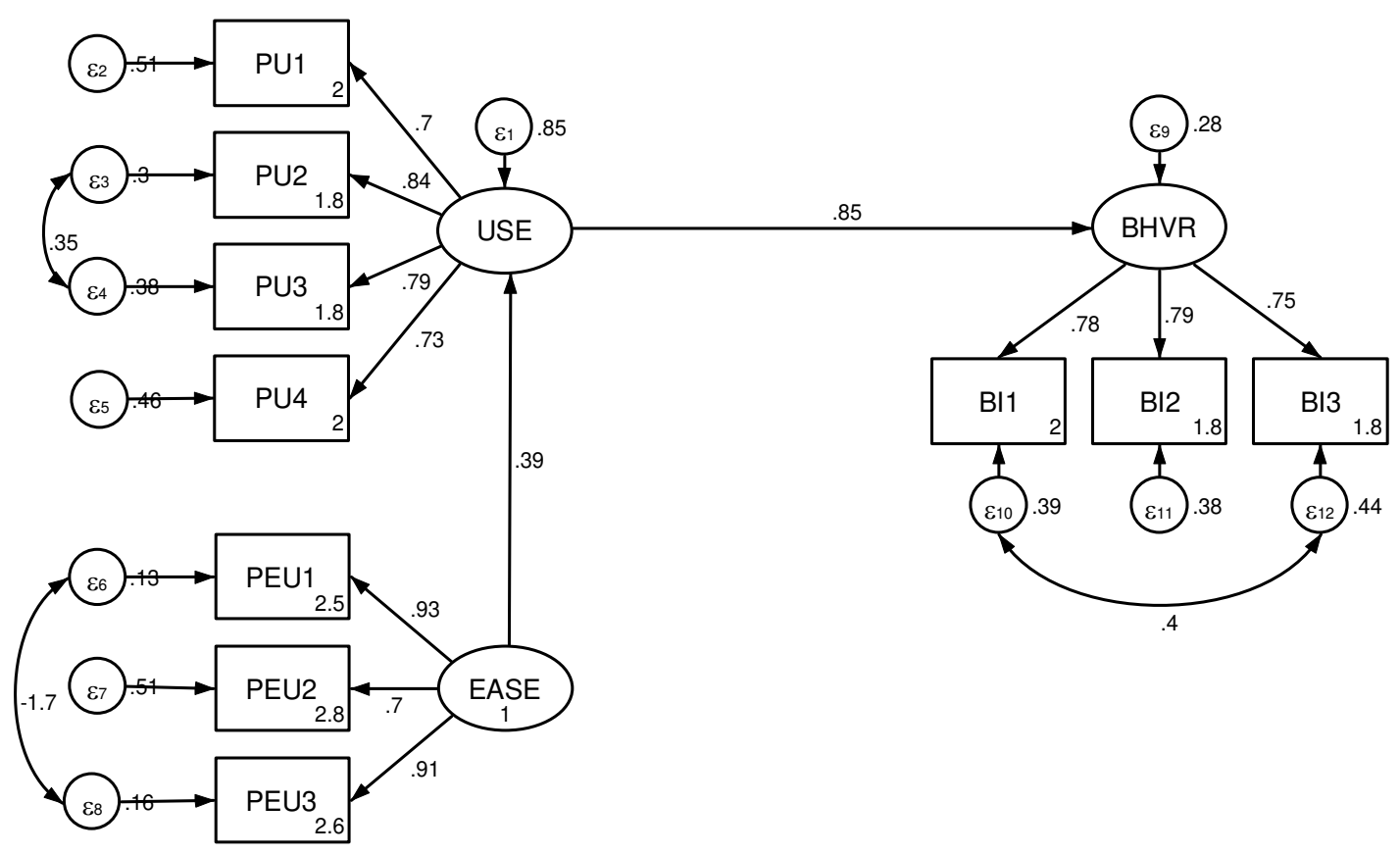

Fig. 4. Structural model

USE $=$ Perceived usefulness; EASE $=$ Perceived ease of use BHVR $=$ Behavioral intention 
The standardized path coefficients shown in Table 4 indicate that only two of the six hypotheses of the theoretical model were accepted.

Table 4. Path coefficients

\begin{tabular}{|l|l|l|l|}
\hline \multicolumn{1}{|c|}{ Dependent variable } & \multicolumn{2}{|c|}{ Hypothesis } & Path coefficient \\
\hline Perceived usefulness & $\mathrm{H}_{1}$ & $\mathrm{PEU} \rightarrow \mathrm{PU}$ & $.39^{\star}$ \\
\hline Behavioral intention & $\mathrm{H}_{5}$ & $\mathrm{PU} \rightarrow \mathrm{BI}$ & $.85^{\star}$ \\
\hline
\end{tabular}

\section{Discussion and conclusions}

The purpose of the study was to (a) identify usage habits of tablet PCs by students at South African higher education institutions (HEIs) and (b) determine which factors influence user-adoption of e-learning technologies. Generally, it was found that students are not fully maximizing use of tablet PCs. It was observed that only the most basic applications are those that are currently being used, and other functionalities and applications that are supported by tablet PCs are yet to be utilized. A possible explanation for students' limited use of the tablet PCs is the fact that they were still familiarising themselves with devices, as a vast majority ( 69 per cent) only became aware of the devices within the last six months at the time of data collection. It, therefore, could be reasonable to suggest that the students are still finding navigating tablet PCs challenging, hence the relatively low path coefficient of perceived ease of use and perceived usefulness, and no relationship whatsoever between perceived ease of use and behavioral intention. This is in stark contrast to perceived usefulness and behavioral intention. The high coefficient of the path between perceived usefulness and behavioral intention highlights the importance of perceived usefulness on students' decision to adopt tablet PCs. This suggests that the less complicated the students perceive tablet PCs, the more likely they will find it useful (Rogers, 1995). Additionally, Rogers (1995) explains that such a scenario where an existing innovation is applied to solve a different problem is called discontinuous innovation. Furthermore, Rogers (1995) explains that innovations usually take time to be fully-adopted and utilized by adopters. Following Roger's (1995) findings, it can be assumed that over time, the number of tablet PC features utilized by students would increase.

In terms of the hypotheses testing, the results found support for two of the six tested hypotheses - H1: Perceived ease of use of tablet PC has a significant effect on the intention towards using it, and $\mathrm{H} 5$ : Perceived usefulness of tablet PC has a significant effect on the intention to use it. Generally, these findings conform to those observed in past studies, that perceived usefulness and perceived ease of use contribute to the development of behavioral intentions (Ma \& Liu, 2004; Masrom, 2007; Yi, Tung, \& Wu, 2003). However, what stands out from this study is the causal structure of the relationship between perceived ease of use, perceived usefulness and behavioral intention. While past studies suggest a direct causal effect between perceived ease of use and behavioral intention (Alrafi, 1989; Masrom, 2007), this study proposes that there is no direct causal effect between these constructs. This should be understood to be a specific case for e-learning and more specifically within the context of discontinuous innovations in elearning settings. Furthermore, this study argues that the absence of causal effect between perceived ease of use and behavioral intention is because users would still be familiarising themselves with the technology, but, as time progresses, users become more familiar and then a direct causal link between perceived ease of use becomes plausible.

For that reason educators are encouraged when designing e-learning programs to anticipate low levels of adoption in the introduction phases of the technology, because at this point, it is often innovators and early adopters that use the technology (Meuter, Bitner, Ostrom, \& Brown, 2005; Rogers, 1995). Therefore, for successful integration of technology into an e-learning approach, marketing is important that highlights product features and also demonstrations, to enforce trialability and observability, which have also been identified as important determinants of adoption (Meuter et al., 2005).

In this current study, structural equation modelling (SEM) proved to be powerful in testing hypothesized effects as opposed to linear regression techniques used in past studies, including the original formulation of the technology acceptance model (Masrom, 2007). One potential drawback of using regression analysis that was minimized by this study, is the failure of regression analysis to take into account errors in the measurement of variables (Hair et al., 2010). For that reason, it was difficult to draw comparisons from past studies, as this study was the first to use SEM to model tablet PC adoption within an e-learning context.

\section{References}

1. Alrafi, A. (1989). Technology Acceptance Model, Engineering, 22 (1982), pp. 1-12.

2. Banister, S. (2010). Integrating the iPod Touch in K-12 Education: Visions and Vices, Computers in the Schools, 27 (2), pp. 121-131.

3. Blumberg, B., Cooper, D.R. \& Schindler, P.S. (2011). Business Research Methods, 3rd European Edition. London: McGraw Hill.

4. Bonk, C.J. (1999). Breakout from learner issues, International Journal of Educational Telecommunication, 5 (4), pp. 387-410. 
5. Calder, B.J., Phillips, L.W. \& Tybout, A.M. (1981). Designing Research for Application, The Journal of Consumer Research, 8 (2), pp. 197-207.

6. Davis, D. (1989). Perceived Usefulness, Perceived Ease of Use, and User Acceptance of Information Technology, MIS Quarterly, 13 (3), pp. 319-340.

7. Field, A. (2009). Discovering Statistics Using SPSS, 3rd Edition. Thousand Oaks, CA: Sage.

8. Hair, J.F., Black, W.C., Babin, B.J. \& Anderson, R.E. (2010). Multivariate Data Analysis: A Global Perspective, 7th Edition. Upper-Saddle River: Pearson.

9. Hooper, V.\& Zhou, Y. (2007). Addictive, dependent, compulsive? A study of mobile phone usage. Paper presented at the 20th Bled eConference eMergence: Merging and Emerging Technologies, Processes, and Institutions, Bled, Slovenia, 4-6 June.

10. Kline, R.B. (1998). Principles and Practice of Structural Equation Modeling. New York: Guilford Press.

11. Lavooy, M. \& Newlin, M. (2003). Computer mediated communication: online instruction and interactivity, Journal of Interactive Learning Research, 14 (2), pp. 157-165.

12. Ma, Q. \& Liu, L. (2004). The Technology Acceptance Model: A Meta-Analysis of Empirical Findings, Journal of End User Computing, 16 (1), pp. 59-72.

13. Malhotra, N.K. (2010). Marketing Research: An Applied Orientation. Upper Saddle River: Prentice Hall.

14. Masrom, M. (2007). Technology Acceptance and E-Learning. Paper presented at the 12th International Conference on Education Sultan Hassanal Bolkiah Institute of Education, 21-24 May.

15. Meuter, M.L., Bitner, M.J., Ostrom, A.L. \& Brown, S.W. (2005). Choosing among alternative service delivery modes: an investigation of customer trial of self-service, Journal of Marketing, 69 (April 2005), pp. 61-83.

16. Nicholas, D., Rowlands, I., Clark, D. \& Williams, P. (2010). Google Generation II: web behavior experiments with BBC, Aslib Proceedings: New Information Perspectives, 63 (1), pp. 28-45.

17. Rammile, N. \& Nel, J. (2012). Understanding resistance to cell phone banking adoptiong through the application of the technology acceptance model (TAM), African Journal of Business Management, 6 (1), pp. 86-97.

18. Rogers, E. (1995). Diffusion of Innovations, 4th edition (4th ed.). New York: The Free Press.

19. Sabry, K. \& Al Shawi, S. (2008). Information systems for higher education: an interactive design perspective, Information Systems for Higher Education, 3 (2), pp. 163-180.

20. Shambare, R. \& Mvula, A.E. (2011). South African students' perceptions of Facebook: some implications for instructors, African Journal of Business Management, 5 (26), pp. 10557-10564.

21. Tanakinjal, G.H. (2006). Short Message Service (SMS) and Banking. (PhD Marketing Colloquium), University of Otago, Otago, New Zealand. Available at: http://eprints.otago.ac.nz/562/.

22. Walczuch, R., Lemmink, J. \& Streukens, S. (2007). The effect of service employees' technology readiness on technology acceptance, Information \& Management, 44 (2007), pp. 206-215.

23. Yi, Y., Tung, L.L. \& Wu, Z. (2003). Incorporating technology readiness (TR), into TAM: are individual traits important to understand technology acceptance? Paper presented at the Diffusion Interest Group in Information Technology (DIGIT) Workshop, Seattle, WA. 